
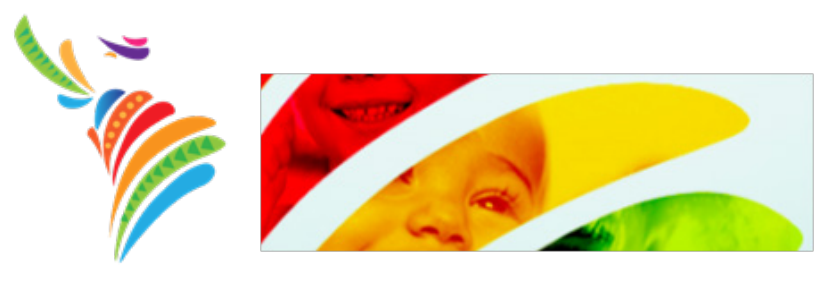

Congreso Odontopediatría 2016 ALOP

\title{
Trabajos premiados en \\ el XVIII Congreso de Odontopediatría ALOP, XXV Congreso Internacional ACOP
}

Comité Académico ALOP

$\mathbf{1}^{\text {er. }}$ Lugar

TRATAMIENTO RESTAURADOR EN MOLARES AFECTADOS POR LA HIPOMINERALIZACIÓN MOLAR-INCISIVO.

ESTUDIO LONGITUDINAL

Autor presentante: Rita Cordeiro

$2^{\text {do. }}$ Lugar

OCLUSIÓN TUBULAR COMO TRATAMIENTO

DE HIPERSENSIBILIDAD CAUSADA POR LA

HIPOMINERALIZACIÓN MOLAR INCISAL:

REVISIÓN NARRATIVA.

Autor presentante: Manuelita Vinagre Cañas

$3^{\text {er. }}$ Lugar

LESIONES TRAUMÁTICAS EN LA CÁTEDRA ODONTOLOGÍA INTEGRAL NIÑOS DE LA FACULTAD DE ODONTOLOGÍA DE LA UNIVERSIDAD DE BUENOS AIRES

Autor presentante: Patricia Maria Felisa Sebelli

HIPOMINERALIZACIÓN MOLAR INCISIVA:

COMPORTAMIENTO CLÍNICO DE RESTAURACIONES

Autor presentante: Karina Lorena Martínez 